\title{
A Student Workload Estimator Tool: Rethinking Modular Credit
}

\author{
Liwen Lai, Bimlesh Wadhwa
}

Department of Computer Science, National University of Singapore, Singapore.

\begin{abstract}
This paper aims to develop a Student Workload Estimator tool for University students. Traditionally, modular credit has been used as a student workload indicator at a purely time-based stage. This needs rethinking keeping in view the changing educational settings. The paper presents a basic student workload model built to assess student workload in a more realistic and detailed manner taking into consideration objective factors as well as subjective factors for personalized model. It presents a mechanism for data collection of course workload as well as of the students' subjective perceptions for the workload estimator. The outcomes are expected to provide more insights than only estimated weekly working hours indicated by modular credit, thus allowing students to make more informed decisions for a suitable academic path and to help reduce the course dropping rate. Deliverables of the work include a data collection tool and a workload estimator tool.
\end{abstract}

Keywords: Data Collection; Modular Credit; Objective Workload; Subjective Workload; Workload Estimator; Student Workload Model. 


\section{Introduction: rethinking modular credit}

One of the common scenarios in university life is that students may always complain about some modules having a too high workload (Kyndt et al., 2013). However, what is the truth behind the "too high workload"?

It has been recognized that workload is a major factor that has a great impact on the quality of study outcome in the studying environment (Kyndt et al., 2013). The current universities are generally following a modular credit system with modular credit (MC) as an indicator of estimated required time for a module. Although the basic modules are holding the same credit value, there are lots of other factors that have an impact on actual workloads objectively and subjectively, including syllabus, students' perceptions and other certain factors. Therefore, is this MC system enough for the workload schedule in higher education?

\section{Rationale for the need of improvement of MC system}

\subsection{Heavy workload can cause bad academic performance}

Singapore students show excellent performance in mathematics, science, and reading. However, it is exacting a heavy emotional price with experiencing high levels of anxiety with a terrible status of school-life balance on them from the high workload (Davie, 2019). Studies also show that around one-third of students choose to drop the modules before the complete in the Organization for Economic Co-operation and Development (OECD) countries, where student workload plays a significant role in this high module dropping rate (Bowyer, 2012). Meanwhile, overload could also result in surface learning rather than deep learning. Students gain the skills necessary for problem-solving during the deep-learning (Lockwood, 1998). The process from the measurement of the students' workload, to evaluation and the update of curricula, is essential for high-quality education and good student performance (Tuncay et al 2009, p. 136). Overall, the well-designed workload could actually benefit both students for better academic performance and higher education institutes for lower module dropping rates.

\subsection{The measurement of workload is hard}

The workload is more than a fixed number of the estimated weekly learning hours that MC indicates (Kember, 2004). Lots of factors can cause a significant challenge to the actual workload, including teaching methods and personal characteristics (Ruiz-Gallardo et al, 2011). Some common quantitative and qualitative workload measurements that have been using now include end-term feedback surveys, reports, online reviews, interviews, focus groups, etc. However, no matter what methodology has been chosen, it is still hard to measure significant accuracy. Individual students may encounter difficulties to record the actual hours devoted to the study (Ruiz-Gallardo et al, 2011). The subjective student's perception of their 
own study work could also vary (Pogačnik et al, 2004, p. 255). Therefore, it is not easy to measure the accurate actual module workload as it could vary from individuals and hard to collect record actual time.

\subsection{No workload estimator for Students}

There is no other reference other than MC for students to sense the difficulty of the modules in our university. Students may look for online comments or seek help from seniors to find out the details about the module reviews. Few universities, like Rice University (Figure 2.31) and The Open University (Figure 2.3-2), have developed workload tools to help students calculate workload based on either research works or individual weekly activities. The tool could also help the teaching team to assign reasonable tasks during the syllabus design. We believe that students in our university will benefit from having a workload tool. This could help both students and the teaching team aiming at better academic performance.

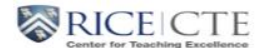

Course Workload Estimator

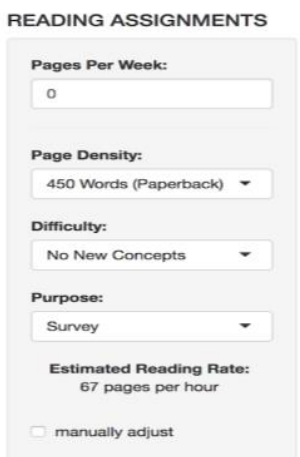

READING ASSIGNMENTS

Pages Per Week:

450 Words (Paperback)

Difficulty:

No New Concepts

Purpose:

Estimated Reading Rate:

manually adjust

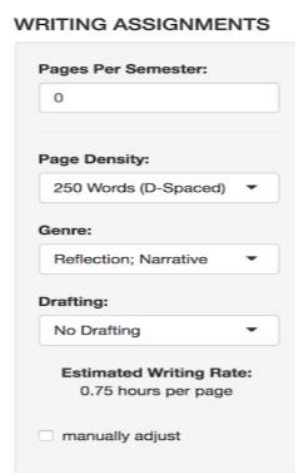

EXAMS

Exarns Per Semester:

0

Study Hours Per Exam:

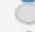

OTHER ASSIGNMENTS

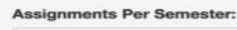

o

Hours Per Assignment:

o

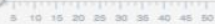

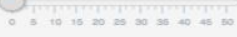

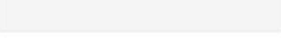

COURSE INFO

Class Weeks (With Exams):

15

ESTIMATED WORKLOAD

O out of class hrs/wk

Estimation Details

Research \& Design Elizabeth Barre

Figure 2.3-1. Rice University Course Workload Estimator.

Source: https://cte.rice.edu/workload 


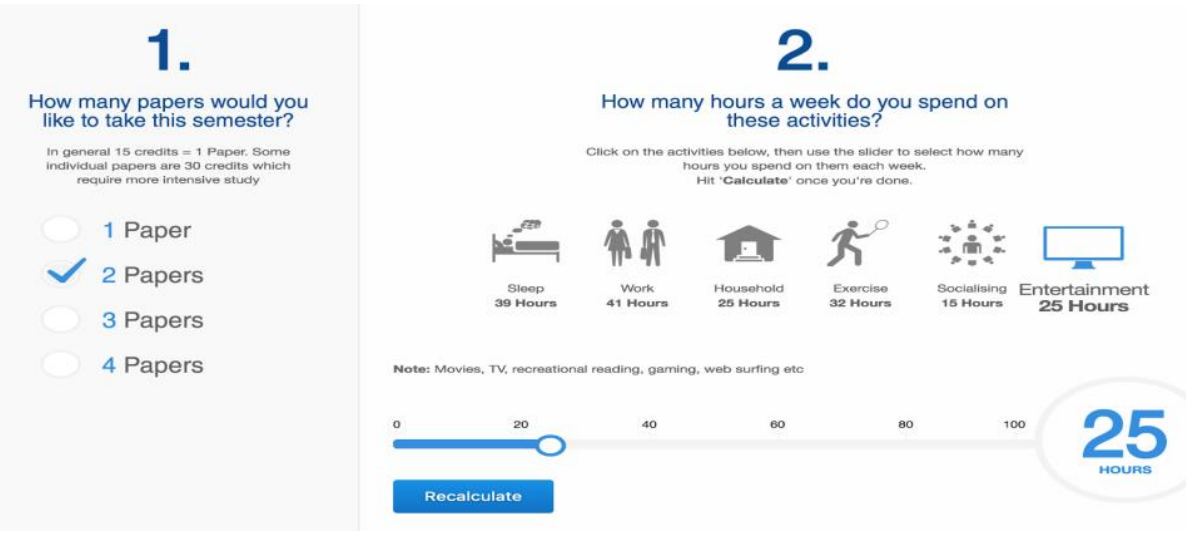

Figure 2.3-2. Massey University Workload Estimator.

Source: https://www.massey.ac.nz/massey/learning/programme-course/planning/workload-planning-

tool/workload-planning-tool_home.cfm

\section{Workload estimator tool structure and functionality}

The proposed tool is developed as a time-tracking utility web application, aiming to help students improve study efficiency through time tracking and customize a workload balanced timetable according to individual preferences. When students leverage the app to keep track of task progress for better time management, the actual time data will be collected for each module and its various components. The data will benefit both students for better schedule management and curriculum designer to adjust the proper module workload accordingly.

\subsection{User study}

To identify the user base and possible market value of the workload estimator tool, a questionnaire was sent out to student groups via the messaging service Telegram around 500 students. The target audience is current undergraduate students including both local and exchange students. We have received 54 responses across faculties and years of study.

Findings:

1. The majority will be discouraged from using the app because of the inconvenience

2. Students have privacy concerns for using the app

3. The majority are looking forward to using the app plan the schedule better

4. The majority of the respondents are interested in knowing how much time their peers put into a module and they are willing to share their own data 
What would prevent you from tracking your study time?

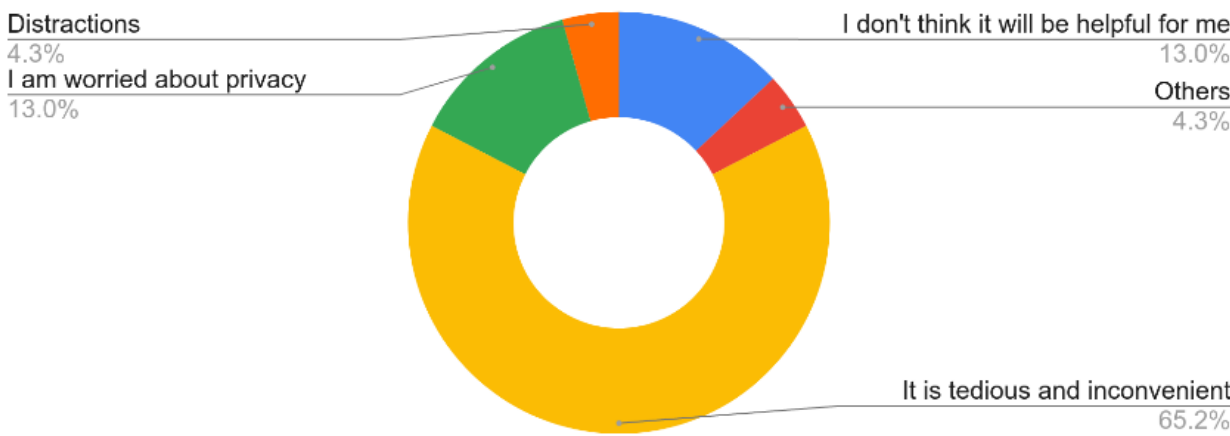

Figure 3.1-1

What would motivate you to track and monitor the time you are spending on your assignments and respective modules?

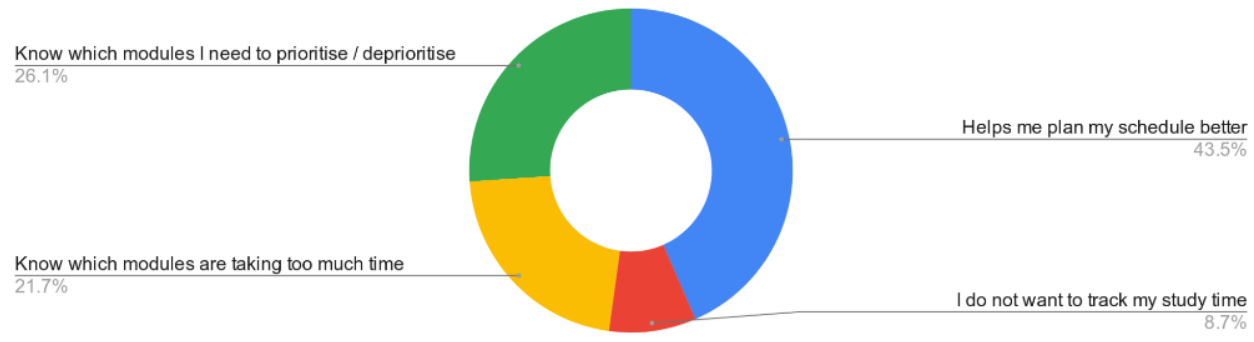

Figure 3.2-2

Will you be interested to know how much time your peers spend on the modules?

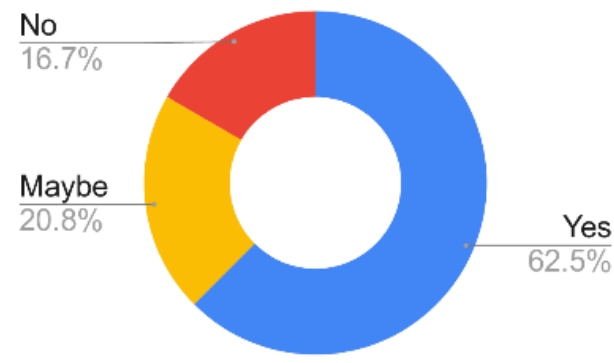

Figure 3.2-3
Would you be willing to sharing your collected time data anonymously?

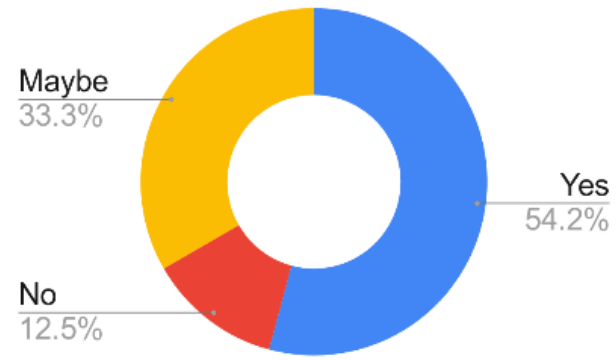

Figure 3.2-4 
Synthesis:

1. The workload tool should be user-friendly to attract users

2. The private data should be kept to students own usage and the usage of data should be under students' consents

3. Social network on the app could attract students

In general, students are experiencing heavy workload and they are looking for a workload management tool with good user experience to design their academic path. Students are looking for the module reviews and are willing to share the data as reviews under the consent.

Students are positive about to- do list and block list to improve study efficiency. A social network could encourage the usage as students are curious about the performance of their peers. Therefore, adding a leaderboard or other gaming system could possibly attract students. Overall, the workload estimator tool should focus on time-tracking and timetable schedule.

\subsection{Main functionality}

Time tracking tool

The workload tool allows students to track and monitor the actual time they spend on a module's assignments, projects, and revision. In this way, students are able to distribute their time for studies and personal life. Compared with a traditional methodology to use end-term feedback to record workload, the actual time spent on the module could be recorded based on individual performance, rather than vague qualitative feedback and possible bias among students from various backgrounds.

\section{Timetable schedule tool}

The workload tool enables aggregation of all the time data of a particular module to be shared with future students as a reference. Based on the historical data from the modules and personal study performance, it allows students to have the ease of mind knowing that the modules they choose to enroll in would not take up excessive time. Module coordinators are able to review and modify a module's workload or allocated modular credits if necessary as well so that a holistic learning environment can be created and each module would transfer adequate knowledge and skills to warrant the module credits allocated. Students will be able to justify the actual workload according to personal preferences. Rather than seeking for seniors qualitative reviews, students could receive more personal justified suggestions as a reference to design their academic path.

\subsection{Student Workload Model}

In order to gain a degree successfully, students are registered under a programme of study engaged in academic learning activities with a certain minimum credit achieved. The 
workload is the estimated time that students need to finish the learning assessments, including modes of instruction (teacher- directed) and learning activities (student-

directed) (Lockwood, 1999). The module credit value is recognized as an indicator of the estimated student workload. Besides, there is a tendency to distinguish the workload into two categories: objective and subjective workload (Kyndt et al., 2013).

\section{Objective workload}

The objective workload is referred to the objective time students spent on their work (Kyndt et al., 2013). However, it is not easy and also not enough. There is very little research about the amount of time it takes the average college students to complete the common assessments. Besides, although two modules may take around the same time to finish, students may still have different visions of the difficulty levels of these two modules. Therefore, MC is insufficient as a standard to represent the module workload.

\section{Subjective workload}

The subjective workload is derived from the combination of the workload required on students and the effects of these requirements on students (Kyndt et al., 2013). It can be divided into two categories: quantitative perceived and qualitative perceived workload. On the one hand, the quantitative perceived workload emphasizes the time aspects of the workload (Kyndt et al., 2013). It is significantly different from the objective workload as the individual perceptions of the available and required time could vary from the actually taken time. On the other hand, the qualitative perceived workload focus on the effects of demand placed upon students. There are various factors, including learning environments, assessment difficulty, personal characteristics, and social network, that could influence the qualitative perception. Students will sense the heavy workload from the feeling of pressure, stress or frustration (Kember, 2004). This will upset the students and directly decrease their learning motivation.

\section{The future of the workload estimator tool}

Student workload has been indicated as the most crucial factor affecting student engaging with the course activities. Overload is one of the main reasons that lead students to choose to drop the course (Lockwood, 1999) and result in surface learning. We should encourage deep learning which is usually inline with a reasonable workload. The workload tool as a timetracking utility web application could help students adjust the proper module workload accordingly while MC is not enough. 


\section{References}

Bowyer, K. (2012). A model of student workload. Journal of Higher Education Policy and Management, 34 (3), 2012, 239-258.

Davie, S. (2019). Singapore students suffer from high levels of anxiety: Study. [online] The Straits Times. Available at: https://www.straitstimes.com/singapore/education/sporestudents-suffer-from-high-levels-of-anxiety-study [Accessed 5 Nov. 2019].

Kember*, D. (2004). Interpreting student workload and the factors which shape students' perceptions of their workload. Studies in higher education, 29 (2), 2004, 165\{184.

Kyndt, E., Berghmans, I., Dochy, F. and Bulckens, L. (2013). 'Time is not enough.' Workload in higher education: a student perspective. Higher Education Research \& Development, 33(4), pp.684-698.

Lockwood, F. (1999). The Design and Production of Self-Instructional Materials. Milton: Routledge.

Pogačnik, M., Južnić, P., Kosorok-Drobnič, M., Pogačnik, A., Cestnik, V. Kogovšek, J. Pestevšek, U., in Fernandes, T. (2004). An attempt to estimate student's workload. J Vet Med Educ, 31(3), 255-260.

Ruiz-Gallardo, J.-R., Casta no, S., Gomez-Alday, J. J., \& Valdes, A. (2011). Assessing student workload in problem based learning: Relationships among teaching method, student workload and achievement. a case study in natural sciences. Teaching and Teacher Education, 27 (3), 2011, 619-627. 